\title{
Relating Nationalism and Political Theory
}

\author{
Kalbfleisch Ramsay \\ Department of Political Sciences, University of Pretoria, Hatfield, Pretoria, South Africa \\ Kalbfleisch_amsay@up.ac.za
}

\begin{abstract}
This paper discusses the limitations of the liberal model of multiculturalism as a conceptual framework suitable for thinking about justice in complex ethnoreligious national contestations by introducing a wide spectrum of its critics. Liberal formulations of multiculturalism, it is argued, do not challenge the underpinning power infrastructure of the polity nor the normative definition of belonging as articulated by the so-called 'majority culture'. Conversely, the polycentric tactic articulated by Nancy Fraser indeed offers the possibility for a counter hegemonic reimagining of the power arrangements. But it does not address how religion may partake in such introspective rethinking. This process does not imply merely a power reconfiguration. It also entails a reassessment and rethinking of the legitimizing ethos of the nation.
\end{abstract}

\section{Keyword: Nationalism; Political Theory}

\section{Introduction}

This oversight is indicative of the disjunction between political theory and the study of nationalism. One characteristic of this disjunction is the inclination to treat the 'nation' and the 'state' as synonymous. Therefore, the point of departure for this effort to link the study of nationalism and ethnoreligious national conflicts to the conceptual frameworks of political theory may be found in David Little's approach to the study of nationalism. At the heart of his approach is recognition of two critical distinctions. The first is the distinction between the two terms of the construct of the nation-state: the 'nation' and the 'state' and the second interrelated distinction is the one between liberal and illiberal ideal typical modes of interpreting state- and nation-hood. Little's approach also highlights the relevance of religion to the imagining and reimagining of nationalisms and thus it supplements the polycentric approach to conflict transformation.

Nationalism is an ideology and movement characterized by the promotion of the interests of a particular nation, especially to the exclusion or detriment of the interests of other nations, with the aim of gaining and maintaining the nation's sovereignty (self-governance) over its homeland. Nationalism holds that each nation should govern itself, free from outside interference (self-determination), that a nation is a natural and ideal basis for a polity and that the nation is the only rightful source of political power (popular sovereignty). It further aims to build and maintain a single national identity-based on shared social characteristics such as culture, language, religion, politics, and belief in a shared singular history and to promote national unity or solidarity (Kulap, Warto, \& Joebagio, 2017). 
Nationalism, therefore, seeks to preserve and foster a nation's traditional culture, and cultural revivals have been associated with nationalist movements. It also encourages pride in national achievements, and is closely linked to patriotism. Nationalism is often combined with other ideologies, such as conservatism (national conservatism) or socialism (socialist nationalism) for example.

\section{Discussion}

This overarching theme derives Rose's refusal to subordinate the everyday to the event. Such a subordination, which underpins most conventional studies of violent conflict she claims, occurs when a given violent event is considered so powerful and unexpected, so horrific and incomprehensible, it comes to occupy a special place in the analysis. This special place, because powerful, comes to mark the general outline of this or that history, but because incomprehensible, comes to also mark an anomaly in the unfolding of this or that history - the anomaly here is basically a moment when civilization is seen to have broken down, and where human barbarity and savagery takes over for a brief moment(Rose, 2001).

Neither does Das counter one form of subordination with another. The Partition of India in 1947 and the assassination of Prime Minister Indira Gandhi in 1984, and of course the riots accompanying those events, play a very important role in her analysis. She does not, for example, isolate the accounting of the events in everyday life from the events in 1984. She does not force the event into the accounts either. She rather approaches the accounts as a site of mediation between every day and event: the accounts neither belong to, nor are apart from, either the event or the everyday. This is more difficult to accomplish than it sounds, and her success in this task is what separates her work from the numerous other ethnographies undertaken in communities that have experienced such violent events. This is best seen in the foundation of Toffler 's approach, which concerns her understanding of how subjects are formed through the complex interplay between the event and the everyday (Toffler, 1984).

Toffler follows Cavell and the later Wittgenstein in asserting that, "the experience of being a subject is the experience of a limit. "The subject here does not invent the world, but rather makes and remakes the world as the world simultaneously makes and remakes the subject." So we end up with a complex picture because this simultaneous process suggests that this picture necessarily contains shifting boundaries. The interplay between subject and world, which primarily takes place in language, is in other words never-ending and non-absolute.

The world does not make pre-determined subjects, and the subject does not simply invent the world because "the subject does not belong to the world: rather, it is a limit of the world." This is where Wittgenstein affirms a "truth" in Solipsism and says that, "the limits of my language mean the limits of my world." The existence of the world can never be known and as such "the world is independent of my will," but it is my world because it is shown in my language.

Thus my will can alter the limits of my world, but not the world as world (i.e., as a referent). So what we end up with is a continuous interplay between the world and subject whereby the limits of the subject's world are forever shifting and changing.

Hence, a subject, already initiated into the world, puts together different fragments of experience, of the subject's world, and develops a totality that must have certain limits or boundaries because the experience of being a subject is not limitless; but this totality cannot be said or thought, and the boundaries are always already incomplete because "what expresses itself in language, we cannot express by means of language (Onuf, 1998). 
This failure of grammar of what we may also call the end of criteria as the experience of the world-annihilating violence .... My interest in this book is not in describing these moments of horror but rather in describing what happens to the subject and world when the memory of such events is folded into ongoing relationships. My wonder and terror is that it is from such fragile and intimate moments that a shared language had to be built and with no assurance that there were secure conventions on which such a language, in fact, could be found (Shetreet, 1999).

The crux of the difference between my project's approach and Toffler lies in the assertion that rather than posit a sphere of so-called world-annihilating violence as pure madness and thus pass this sphere over in silence to directly tackle the problem of so-called world-annihilating violence and examine the relationship between violence and language in the very sphere where such a relationship supposedly dissipates or never forms all. In other words, while to agree with Toffler 's positive sense regarding the inability of language to express violence (the role of silence), This different stance essentially concerns a shift of emphasis from what is expressed, or is not expressed, to the realm of (un)know ability. Thus, despite the many strengths of her approach, Das in my view leaves an area of potential study unexamined. To get to that area, I will first move through the three aforementioned themes as they take shape in Toffler's work. I begin with the pivotal theme of violence and language (Toffler, 1984).

In other words, the silence of the suffering person relative to certain violent episodes is itself a communication of one's pain. The burden is shifted to the listener here, not the narrator, to understand the pain of the other - not as something that can be observed on the basis of scientific criteria (e.g., searching for a quantitative measure of the pain), but felt on the basis of social criteria (e.g., seeing how one inhabits the world of Joss and devastation). The latter criteria are basically attentive to both the words of the subject (what the subject voices) and the body of the subject (what the subject shows). Das does not, however, attribute words to the former and gesture to the latter. The ethnographer has to be attentive to how words can show one's numbed relation to life just as gesture can tell us what forms of life, what forms of dying, become the soil on which words can grow or not (Bateman, 2004).

This moves us into the second theme - the interplay between founding and maintaining violence. Before going any further should mention that these terms should not be read literally in Das, but rather with the following qualification: Das does not maintain that violent events corrupt or disrupt "pristine" or "non-violent" moments that allegedly existed prior to the violent events of the Partition for example.

The figure of the abducted woman emerged in nationalist state discourse through a sexual contract that allowed the institution of a masculine social contract - both contracts were part of the state's inaugural moment. In this case, state discourse "recognized their [women's] suffering as relevant only for the inauguration of sovereignty.

Here, Elon avoids the determinism of the state-centric view by highlighting how women still manage to form their subjectivity despite the suffocating influence of state discourse at the same time that she does not downplay such influence. Elon undertakes this maneuver by first describing the oscillation between what she calls the "rational-bureaucratic organization" of the state and the "magical" form of the state (Elon, 1971).

This for Bateman explains why in scenes of violent riots, the crowds may chant in the name of the law. The lines between the founding and maintaining violence of the law are blurred because of state oscillation between a rational and a magical mode, not only during times of exception or crisis, but as an on-going process in the everyday (Bateman, 2004).

Whether through rumor or whether through official public inquiries into state practices, the lines between what is legal and illegal are always questioned in the everyday relationships of local 
communities. The process of legitimization that begins in the inaugural moment of the state (founding violence) does not cease there, but continues in the maintaining violence of the state, where it can be observed most poignantly in the life of the community. While such spaces are marginal to the state, Das claims that they are certainly not peripheral either to the community itself or analytically speaking. State discourse cannot simply manipulate or produce subjects in local communities because the state signature on the law cannot lay full or complete claim on what is written in the law (Salfiti, 1997).

The founding violence of the state, then, does not cease with its officially announced end (i.e., rioters have returned back to their homes, order restored, killings, abductions, and destruction have ceased, etc.), but is the moment when such violence is only beginning. Violence seeps into the on-going everyday relationships, and it is in the unfolding of life in the everyday that this founding violence keeps moving (Salfiti, 1997).

Two directions can be taken from this point. The first Das associates with Achille Mbernbe's work, which Das admires but is hesitant to accept. According to Das, Mbembe traces the African failure at selfwriting (i.e., the persistence in writing Africa primarily through tropes of war, devastation, famine, etc. - in other words, through the trope of victimhood and not subjecthood) to a series of denials that fail to directly face the horrors of Africa's past. The problem for Mbembe then becomes concerned with how we, in the present, can recover and master the memory of the horrific past, and resolve the unfinished story of the victims and survivors. In this way, it is hoped that nihilistic escape from the past can then turn into affirmative self-writing; victim can turn into agent.

The second direction is Beckford own. Rather than view unclaimed experiences of the past (blindness) as "escape," Beckford introduces the possibility that subjectivity can be formed through a gesture of mourning that inhabits the world of devastation with the fult understanding that parts of that world are lost forever and thus cannot be reclaimed or recovered. So Beckford does not see the problem as one of "writing the self," which only focuses on what language can or cannot express and how; but rather focuses on the "contrast between saying and showing" in understanding how subjects are already affirmatively forming their subjectivity even when they are seemingly blind to their horrific past. This contrast is what allows Beckford to explore words and gestures that point us towards ongoing everyday practices of dealing with, and living in, what is inexpressible. Descent into the ordinary shows the complex ways in which subjectivity is (re)made by dealing with violence through everyday means. These means, these forms of inhabiting the world in a gesture of mourning, are not marked by what is conventionally understood as extraordinary acts, but by their careful attendance to limits (whether the limits of official state discourse, or the walls of silence that cannot be breached), and the careful/slow transgression of these very same limits (Beckford, 1989).

Time for Campbell can only work on what is accessible, which is not to say that the violence that seeps into the everyday is easy to deal with and readily open for the work of time, of re-writing and overwriting everyday relationships. Extreme care is needed (e.g., observing the interplay between word and gesture) to understand the full scope of what this difficult process entails in both its successes and failures. For example, Campbell finds the work of time in the feeling of the aforementioned absence that some women embodied by sitting in stillness, as if Jelling their unclaimed and unspoken experiences speak for themselves through gesture, building relationships with the dead by a gesture of mourning which understands that it takes a stone-like gesture to speak with what has been turned into stone (Campbell, 1981).

Another example is the language of rumor, which has the ability to ignite acts of carnival-like violence (where crowds act in ways that they normally would not) because the words of rumor arc free of authorship. These are words that can be repeated by anyone at any time to touch a past that is frozen but, because inerrable in the manner of floating words, is a past that does not, as Das 
observes, have a "feeling of pastiness about it." Words describing what they did, how we suffered, how we lost, how they were animals and we were things, how they defied the law and we must restore it - all of these words are floated through a crowd that can then distance itself from its violent actions as far as the words are distanced from the crowd: authorship disappears. Das sees the work of the everyday as countering this tendency, and the task of anthropologists is thus to observe the processes "through which victims and survivors affirm the possibility of life by removing it from the circulation of words gone wild - leading words home, so to speak."

In the predicative moment, the contraction of the face is judged as a wince, which suggests a state of being in pain; in the proclamatory moment, the fact that we share what a wince is, as opposed to a tic for instance, is what shows itself as the condition making our communication possible.

The notion of a deficient stock of knowledge is the direction that traditional philosophy, as opposed to ordinary language philosophy, moves into. Traditional philosophy claims that persons fail because they have not mastered a language (its logics, vocabulary, precise meanings, etc.), hence the necessary vagueness of ordinary language and the consequent suggestion in traditional philosophy that only a sustained philosophical effort can succeed in the mastery of language. In ordinary language philosophy, the notion of mastering a language (via the master language of philosophy) is done away with, and the emphasis shift towards the lack of sufficient initiation of persons into the world (Shetreet, 1999).

In her reading of Wittgenstein, Wittgenstein understood as well as anyone the notion that it is ultimately our shared "forms of life" that are already in our language (or that we are initiated into when we learn language), which make our communication possible. These are not pre-arranged agreements that people systematically come to, and we can never know in advance the depth of our agreement or what we accept as mutual between us . Citing Cavell's work, Wittgenstein puts it as follows: "this agreement is a much more complicated affair [than consensual understandings of agreement] in which there is an entanglement of rules, customs, habits, examples, and practices. Indeed, Wittgenstein asserts that, "language did not emerge from some kind of ratiocination" (Wittgenstein, 2006: 62e, section 475), and our shared conventions are not born of our agreement of opinion but of our shared forms of life, that is, "it is what human beings say that is true and false; and they agree in the language they use." (Wittgenstein, 1973: 88e, section 241; original emphases) And as Cavell puts it, what Wittgenstein consequently finds so astonishing is "that the extent of agreement is so intimate and pervasive; that we communicate in language as rapidly and completely as we do." (Cavell, 1979: 31)

My propositions serve as elucidations in the following way: anyone who understands me eventually recognizes them as nonsensical, when he has used them - as steps - to climb up beyond them. (He must; so to speak, throw away the ladder after he has climbed up it.)

In short, Gadamer is better at illustrating the dialectical element of interpersonal communication than Wittgenstein is (Linge, 1977: xxxvii-xl). And this is made possible because Gadamer does not throw out transcendence with one failed attempt at it; simply because transcendence, by definition, is the very mark of our shortcomings as finite beings. So my attention will now move towards an understanding of how this transcendental element relates to language in a manner that does not treat transcendence as an ascending movement beyond the ordinary and towards non-sense or madness, but rather in a manner that focuses on how transcendence constitutes our shortcomings as finite beings whereby the "thing itself' will always evade interpretation - remains "over there" in Gadamerian terms - at the same time that it plays a role in the fusion of horizons. This different understanding of transcendence will guide the discussion of violence the "thing itself'. 


\section{Conclusion}

To help address this gap, Action to End Domestic Violence initiative will increase the capacity of new and established Deaf organizations to address domestic violence. When people suffering violence can't communicate with those that could help them, they are essentially shut off from services that should be accessible to all survivors," said Nancy Smith, director of Vera's Center on Victimization and Safety. "By expanding the vital work of organizations who are often the only ones capable of responding to these calls, we will help deafer survivors safely flee from abuse, heal from trauma, and find justice."

Both the Translating Justice and Deaf Action initiatives build upon Vera's longstanding work in improving language access for immigrant and Deaf individuals. Since 2005, Vera has been working with victim service providers, law enforcement, and other justice system officials to overcome language and cultural barriers in serving diverse communities, including through publishing guides and providing training.

The transcendental evasiveness that fuses horizons is essentially part of the ground for the concept of violence the "thing itself." It is also important to mention at this point that Derrida's intervention in the following chapters will form another part of this ground, ensuring that this ground will be a sort of groundless ground, thus maintaining that element of incessant movement or flux inherent to violence that discussed in the Introduction and chapter one. Through Gadamer and Derrida, we can begin to see how violence evades interpretation for both analyst and actor, and how violence may produce fused horizons joining participants in a communion born of dialogue.

\section{References}

Al-'Ulaymi, M. ai-D. (1968). AI-Uns al-falil fi Tarikh al-Quds toa'l-Kbalil. Najaf: al-Matbaa al-Haydariyya.

Ashrawi, H. (1994). This Side of Peace. New York: Simon and Schuster.

Devlin, J. F. (1992). Effects of leadership style on oil policy.

Fachrurozi, M. H. (2017). The Abdul Rivai's thought of Nationalism in the Bintang Hindia Newspaper. International Journal of Multicultural and Multireligious Understanding, 4(6), 72. https://doi.org/10.18415/ijmmu.v4i6.94

Friedland, R. (2001). Religious Nationalism and the Problem of Collective Representation. Annual Review of Sociology, 27(1), 125-152. https://doi.org/10.1146/annurev.soc.27.1.125

Gurr, T. D. (1993). Minorities at Risk: A Global View of Ethnopolitical Conflicts. Washington, D.C: Institute of Peace.

Hunt, C. and L. H. (1980). Sociology (Fifth Edit). New York: McGraw-Hill.

Hutchinson, J. (1994). Nationalism (A. D. Smith, ed.). Oxford-New York: Oxford University Press.

Katzenstein, P. J. (1996). The Culture of National Security Book by. Columbia University Pres,.

Kulap, M., Warto, M., \& Joebagio, H. (2017). Nationalism of Nani Wartabone: Nation Character Building Foundation of Indonesia. International Journal of Multicultural and Multireligious Understanding, 4(3), 12. https://doi.org/10.18415/ijmmu.v4i3.69 
Lijphart, A. (1984). Democracies. Patterns of Majoritarian and Consensus Government in Twenty-one Countries. New Haven: Yale University Press.

Rich, N. (1985). Why the Crimean War? A Cautionary Tale. Hanover: University Press of New England.

Tibi, B. (1997). Arab Nationalism (3rd ed.). New York: Martin's Press.

\section{Copyrights}

Copyright for this article is retained by the author(s), with first publication rights granted to the journal.

This is an open-access article distributed under the terms and conditions of the Creative Commons Attribution license (http://creativecommons.org/licenses/by/4.0/). 